\title{
Overview and Future Potential of Fast Dissolving Buccal Films as Drug Delivery System for Vaccines
}

\author{
Mohammad Uddin ${ }^{1}$, Amanda Allon ${ }^{1}$, Monzurul A. Roni ${ }^{2}$, Samir Kouzi ${ }^{3}$ \\ ${ }^{1}$ College of Pharmacy, Larkin University, Miami, FL; ${ }^{2}$ College of Medicine, University of Illinois, Peoria, IL; School of \\ Pharmacy, Wingate University, Wingate, NC, USA.
}

Received, May 24, 2019; Revised, July 29, 2019; Accepted, July 30, 2019; Published, July 31, 2019.

\begin{abstract}
Vaccination is considered one of the most successful public health interventions of the modern era. Vaccines are categorized based on the antigen used, delivery system and the route of administration. Traditional vaccines are produced from the dead, attenuated or inactivated pathogens that cause disease. However, newly developed vaccines are DNA based, liposome based, and virus like particle (VLP) based which are more effective and specific to some malignant diseases. The delivery system of vaccines has been advanced along with time as well. New delivery systems such as nanoparticles, liposomes, or cells (for DNA) has been proven to develop a more efficient vaccine. Most vaccines are administered via intramuscular (IM), subcutaneous (SQ) or oral (PO) route. However, these routes of administration have limitations and side effects. An alternative route could be oral cavity administration such as buccal or sublingual administration using film dosage form as delivery vehicle. In this article, we thoroughly reviewed the possibility of developing a quickly soluble film-based delivery system for vaccine administration. We reviewed the different types of new vaccines and vaccine formulations such as VLP based, liposome, bilosome, particulate, and summarized their suitability for use in a film dosage form. Quickly soluble film dosage form is the most optimized form of buccal administration. A film dosage form applied in the buccal cavity has several advantages: they can avoid first pass effect, they are easy to administer and prepare, and they are more cost effective. Since there is no first pass effect, only a small quantity of the vaccine is needed. Vaccines in their original form or in a nano or microparticulate form can be used in a film. The film can also be developed in multilayers to protect the vaccine from degradation by saliva or swallowing. Films are easy to prepare, administer, and can be used for systemic and local action. In addition, most of the current vaccines use mostly the parenteral route of administration, which has some major drawbacks such as poor induction of mucosal immunity, less patient compliant, less potent, high cost and cumbersome production process. Sublingual and buccal vaccine delivery can be good alternatives as they are easier to prepare and safer than parenteral administration routes. The buccal and sublingual administration have the advantage to produce both systemic and mucosal immunity.
\end{abstract}

\section{INTRODUCTION}

Vaccination against fatal diseases has been the prime focus to protect public health. It is the goal of the scientists to develop methods to stimulate the immune system to target malignant cells and destroy them efficiently. Vaccination has been proven to be the best option for the improvement and maintaining public health globally. Vaccines are the most costeffective means of preventing a variety of formerly common and deadly infectious diseases. However, vaccination against established malignancy has been largely disappointing [1]. More than 40,000 adults in the United States die each year from vaccinepreventable diseases, such as influenza or pneumococcal diseases, or complications from the diseases, such as pneumonia [2]. Increasing vaccination rates could help reduce the toll from these illnesses. Also, many diseases that are rare in the developed countries remain endemic in the third world due to the lack of healthcare system, or limited access to refrigeration, cold chain storage system etc. The current most common vaccines are measles, mumps, rubella (MMR combined vaccine), rotavirus, smallpox, chickenpox, yellow fever, shingles, Hib (Haemophilus influenzae type b) disease, hepatitis B, HPV (human papillomavirus), whooping cough (part of the DTaP combined vaccine), pneumococcal, meningococcal etc. Almost all of these are administered in liquid dosage form

Corresponding Author: Dr. Mohammad Uddin, College of Pharmacy, Larkin University, Miami, FL; Email: MUddin@ularkin.org 
and administered orally, subcutaneously, or intramuscularly.

Different routes of administration of vaccines have advantages and disadvantages. Vaccines for intramuscular administration are expensive to prepare, require cold chain storage and trained personnel. On the other hand, oral vaccines are more patient compliant, easy to administer, no need for cold chain storage system and trained personal. Also, oral vaccines can have the potential to stimulate mucosa-associated lymphoid tissue (MALT) located in the digestive tract and the gut associated lymphoid tissue (GALT), both of which are important for the induction of effective mucosal response against many viruses [3]. In addition, drug or vaccine can be administered via oral route in many different forms such as liquids, capsules, tablets, chewable tablets, etc.

Oral administration is the most preferred from patient's perspective because it is the most convenient, cost-effective, and easy to use. Although highly desirable, oral route has some major limitations that need to be improved for an effective vaccine formulation. These include poor bioavailability, degradation of vaccine by enzyme or harsh acidic condition of the body, inconsistent drug concentration, and taste issues. Bioavailability is the major concern for an orally administered vaccine which leads to a great need for identifying better options for higher efficacy.

One of the solutions to overcome the oral administration issue was fast dissolving drug delivery systems, which were first invented in the late 1970 s as to overcome swallowing difficulties associated with tablets and capsules for pediatric and geriatric patients. Although placed in oral cavity, the administration of drug via sublingual and buccal are different from oral (per oral, PO) administration. Unlike oral, sublingual or buccal are systemic, directly approachable to blood. Instead of passing through the GI tracts such as esophagus, stomach or intestine, drug can directly enter to the blood through the membrane. Medications taken by buccal or sublingual administration provide consistent drug concentration levels in the blood, dissolves quickly, have immediate onset of action, and can avoid the first pass effect. Since there is no first pass effect, the bioavailability is high. Therefore, less amount of the drug, in comparison with oral administration, can be used to elicit desired effect. Also, in case of sublingual or buccal the patient does not need to swallow the drug. Another advantage of buccal and sublingual is that they do not subject proteins and/or peptides to the degradation usually caused by gastrointestinal administration.

The most important advantage of buccal and sublingual administration is probably that if vaccine is administered, it can produce both systemic and mucosal immunity [4]. Most of the pathogens infect their host through the mucosa, therefore an ideal vaccine should induce protective immunity at mucosal sites in order to act as a first line of defense against infections. However, most of the vaccines currently in use are administered via injection such as subcutaneous or intramuscular route and have very limited mucosal immunity. The limitation of these routes is that they induce poor mucosal immunity, whereas vaccines administered via mucosal routes have proven to be effective for the induction of both systemic and local immunity [5]. Additionally, mucosal immunization such as sublingual and buccal makes vaccine delivery easier and safer than parenteral administration routes. These are very suitable for mass immunization during pandemic situations and improves acceptability especially among children [6]. Therefore, mucosal administration of vaccine via buccal or sublingual could be a great choice for mass protection. Among the two, buccal drug delivery was identified as a better option for oral administration.

Various bio adhesive mucosal dosage forms have been developed, which includes adhesive tablets, gels, ointments, patches, and more recently the use of polymeric films or mouth dissolving films for buccal delivery [1]. A quickly soluble tablet or film dosage form can be used as drug career for buccal administration. The quickly soluble oral film dosage form has several advantages over other dosage forms for vaccines or drugs. Lower bioavailability of oral solid drugs, inconvenience of administering injections, inaccurate dosing by liquid formulations have turned the focus of pharmaceutical companies to develop oral film forms of medications that eliminate several of these limitations. Oral films are easy to prepare, administer, and handle. Normally, any biodegradable and biocompatible polymer can be used to prepare the film including any other material needed such as permeation enhancer, plasticizer etc. in a simple method. In this review article we intend to evaluate the potential use of quickly oro-soluble film dosage forms for vaccine delivery. 


\section{CONVENTIONAL VACCINES AND THEIR ADMINISTRATION}

There are mainly five types of vaccines. These are live, inactivated, subunit, toxoid, and conjugate vaccines. Additionally, there are two types of vaccines that still in the experimental stages but show great promise. These are DNA, and recombinant vector vaccines [7]. Current conventional vaccines with their antigen, species used, manufacturer and route of administrations are listed in Table 1.

Live vaccines use a weakened (or attenuated) form of the pathogens that cause a disease. As these vaccines are like the natural infection, they can produce strong immune response and can have longlasting effect. Only 1 or 2 doses of most live vaccines are enough to produce desired immune effect [7]. However, live vaccines have some limitations in terms of production, handling and side effect. Extended safety is required to handle the vaccine production when live viruses are used as antigen. Extra caution should be taken in certain populations - such as people with weakened immune systems, long-term health problems, or people who've had an organ transplant [7]. Another limitation is live vaccines need to be well preserved in cold storage system which limits their mass use in underprivileged countries where mass vaccination is mostly needed [8]. Live vaccines protect against diseases such as measles-mumps-rubella, rotavirus, smallpox, chickenpox, yellow fever, and shingles. Liquid dosage forms of the vaccines are administered via subcutaneous or oral route (Table 1).

Inactivated vaccines use the killed version of the antigen (bacteria) that causes a disease. Inactivated vaccines usually do not provide immunity as strong as live vaccines, multiple doses are required in which several booster doses are followed by the prime dose. Inactivated vaccines are more stable and safer than live vaccines since dead microbes can't mutate back to their disease-causing state. Another advantage of inactivated vaccines is these do not require any cold storage, therefore can be easily stored and transported in a freeze-dried form or powder form. This provides a great option for inactivated vaccines to be used in underprivileged countries [8]. Inactivated vaccines are used to protect against hepatitis A, flu, polio, and rabies. Inactivated vaccines are administered in suspension form and the common routes of administration for these vaccines are intramuscular, subcutaneous, and intradermal (Table 1).

Subunit vaccines use only a part of the pathogens to stimulate the immune system instead of using the entire microbe. In some cases, these vaccines use epitopes - the very specific parts of the antigen that antibodies or T cells recognize and bind to [7]. Since subunit vaccines contain only the essential part of the antigens and not the whole microbes, the chances of adverse reactions to the vaccine are lower [8]. A recombinant subunit vaccine has been made for the hepatitis B virus, and research is ongoing on a recombinant subunit vaccine against hepatitis $\mathrm{C}$ virus [7]. Subunit vaccines are administered in solution form via intramuscular (IM) or subcutaneous (SQ) form (Table 1).

Conjugate vaccines are like subunit vaccines. Conjugate vaccines only use a small part of a bacterium linked to a carrier protein. Some bacteria possess an outer coating of sugar molecules called polysaccharides. Polysaccharide coatings disguise a bacterium's antigens so that the immature immune systems of infants and younger children cannot recognize or respond to them. Conjugate vaccines, which are a special type of subunit vaccine, get around this problem [8]. Conjugate vaccines are used to create a more powerful, combined immune response: typically, the part of the bacteria being presented would not generate a strong immune response on its own, while the carrier protein would. The piece of bacteria can't cause illness but combined with a carrier protein can generate immunity against future infection. Conjugate vaccines are used to protect against haemophilus influenzae type B (Hib) (Table 1).

A toxoid vaccine is produced from the toxin secreted by bacteria. They use a toxin made by the pathogens that causes the disease thus, they create immunity to the parts of the pathogen that cause a disease instead of the pathogen itself. Therefore, the immune response is targeted to the toxin instead of the whole pathogen [7]. Toxoid vaccines are used to protect against diphtheria and tetanus. These are administered in suspension form via intramuscular route (Table 1). 
Table 1. Current marketed vaccines with antigen, species used, dosage form and route of administration

\begin{tabular}{|c|c|c|c|c|}
\hline Vaccine Type & Disease & Antigen and species used & Dosage form & $\begin{array}{l}\text { Route of } \\
\text { administration }\end{array}$ \\
\hline \multirow[t]{6}{*}{ Live } & $\begin{array}{l}\text { Measles, Mumps, } \\
\text { Rubella (MMR) }\end{array}$ & $\begin{array}{l}\text { Live attenuated virus grown in chick } \\
\text { embryo culture (measles, mumps) } \\
\text { and human diploid lung fibroblast } \\
\text { (rubella) [95] }\end{array}$ & Diluent & Subcutaneous (SQ) \\
\hline & Varicella (VAR) & $\begin{array}{l}\text { Live attenuated virus grown in } \\
\text { human diploid culture (MRC-5) [96] }\end{array}$ & Suspension & Subcutaneous (SQ) \\
\hline & Zoster (HZV) & $\begin{array}{l}\text { Live attenuated virus grown in } \\
\text { human diploid culture (MRC-5) [97] }\end{array}$ & Suspension & Subcutaneous (SQ) \\
\hline & Yellow Fever & $\begin{array}{l}\text { Virus grown in living avian leucosis } \\
\text { virus free chick embryo [98] }\end{array}$ & Diluent & Subcutaneous (SQ) \\
\hline & Cholera & $\begin{array}{l}\text { Fermented in medium containing } \\
\text { yeast extract }[99]\end{array}$ & Suspension & Oral \\
\hline & Rotavirus (RV) & $\begin{array}{l}\text { Grown in monkey kidney cells or } \\
\text { vero cells }[100]\end{array}$ & $\begin{array}{l}\text { Suspension } \\
\text { Solution }\end{array}$ & Oral \\
\hline \multirow[t]{4}{*}{ Inactivated } & Polio (IPV) & $\begin{array}{l}\text { Live inactivated virus grown in } \\
\text { monkey kidney cells or vero cells } \\
{[101]}\end{array}$ & Suspension & Subcutaneous (SQ) \\
\hline & $\begin{array}{l}\text { Hepatitis A } \\
\text { (HepA) }\end{array}$ & $\begin{array}{l}\text { Grown in human diploid culture } \\
\text { (MRC-5) [102] }\end{array}$ & Suspension & Intramuscular (IM) \\
\hline & Rabies & $\begin{array}{l}\text { Grown in human diploid culture } \\
\text { (MRC-5) [103] }\end{array}$ & $\begin{array}{l}\text { Suspension } \\
\text { Diluent }\end{array}$ & Intramuscular (IM) \\
\hline & $\begin{array}{l}\text { Haemophilus } \\
\text { influenzae (Hib) }\end{array}$ & $\begin{array}{l}\text { Polysaccharide purified from culture } \\
\text { of haemophilus influenzae and } \\
\text { conjugated to a carrier protein } \\
\text { such as inactivated tetanus toxoid, or } \\
\text { the outer membrane vesicle protein } \\
\text { of Neisseria meningitidis serogroup } \\
\text { B11 [104, 105] }\end{array}$ & $\begin{array}{l}\text { Suspension } \\
\text { Solution }\end{array}$ & $\begin{array}{l}\text { Intramuscular (IM) } \\
\text { Intradermal (ID) } \\
\text { Intranasal (IN) }\end{array}$ \\
\hline \multirow[t]{3}{*}{ Subunit } & $\begin{array}{l}\text { Hepatitis B (Hep } \\
\text { B) }\end{array}$ & $\begin{array}{l}\text { Recombinant expression of HBsAg } \\
\text { protein, as virus-like particles, in } \\
\text { yeast cells [107] }\end{array}$ & $\begin{array}{l}\text { Suspension } \\
\text { Solution }\end{array}$ & Intramuscular (IM) \\
\hline & $\begin{array}{l}\text { Human } \\
\text { papillomavirus } \\
\text { (HPV) }\end{array}$ & $\begin{array}{l}\text { Recombinant vaccine prepared from } \\
\text { virus like particle of HPV protein in } \\
\text { yeast [108] }\end{array}$ & Suspension & Intramuscular (IM) \\
\hline & $\begin{array}{l}\text { Meningococcal } \\
\text { Group B (MenB) }\end{array}$ & $\begin{array}{l}\text { Recombinant proteins (neisserial } \\
\text { adhesion A, neisserial Heparin } \\
\text { binding antigen, factor H binding } \\
\text { protein) are individually produced in } \\
\text { E.coli [109] }\end{array}$ & Suspension & Intramuscular (IM) \\
\hline Conjugated & $\begin{array}{l}\text { Pneumococcal } \\
\text { conjugate (PCV13) }\end{array}$ & $\begin{array}{l}\text { Streptococcus pneumoniae serotypes } \\
\text { grown individually in soy peptone } \\
\text { broth and conjugated with diphtheria } \\
\text { protein carrier [110] }\end{array}$ & Suspension & Intramuscular (IM) \\
\hline Toxoid & $\begin{array}{l}\text { Diphtheria, } \\
\text { tetanus, \& } \\
\text { acellular pertussis } \\
\text { (Dtap) }\end{array}$ & $\begin{array}{l}\text { Diphtheria toxin extracted from } \\
\text { fermentations of Corynebacterium } \\
\text { diphtheria. Tetanus toxin extracted } \\
\text { from fermentations of Clostridium } \\
\text { tetani. Whole Bordetella pertussis } \\
\text { grown in fermenters [106] }\end{array}$ & Suspension & Intramuscular (IM) \\
\hline
\end{tabular}




\section{LIMITATIONS OF CONVENTIONAL VACCINES}

A route of administration is the path by which a drug or vaccine is taken into the body. A substance must be transported from the site of entry to the part of the body where its action is desired to take place. Vaccines have many different routes of administration, including Intramuscular (IM), Subcutaneous (SC), Intradermal (ID), Oral administration, and intranasal spray [9]. Intramuscular injections are administered into the muscles. Vaccines containing adjuvants should be injected IM to reduce adverse local effects. Subcutaneous injections are administered into the skin, just under the topmost layer into the fat. Intradermal (ID) injection administers the vaccine in the topmost layer of the skin [9]. In oral administration, vaccines are taken up through the mouth in liquid form. Oral administration of vaccine makes immunization easier by eliminating the need for a needle and syringe. Intranasal spray application of a vaccine offers a needle-free approach through the nasal mucosa of the vaccine [9].

Most of the vaccines are currently given by intramuscular injection (IM) [9]. Although IM injections are most common and are easy to administer, they unfortunately have quite a few side effects. These include but not limited to pain, swelling, and erythema $[10,11]$. Other severe adverse effects, such as severe headache with hypertension, gastroenteritis, and bronchospasm, also occurs [10]. One may also experience severe pain at the site of intramuscular injection. Redness, swelling or warmth are possible if the administration was not properly conducted. There may also be drainage or bleeding at the injection site. General discomfort is quite common, tingling or numbness can occur as well. There may be allergies depending on the drug, as well as the person's vulnerability to various allergens. Anaphylaxis is a potentially lifethreatening allergic reaction, which can occur after many different exposures, e.g., food, drugs, or vaccines. Virtually all vaccines have the potential to trigger anaphylaxis. Despite its rarity, anaphylaxis is a potentially life-threatening medical emergency that vaccine providers need to be prepared to treat [12]. It's also normal to have some anxiety about receiving an injection, especially an intramuscular injection due to the long needle. The intramuscular vaccine injections are invasive, expensive, require cold chain storage and trained personnel for administration [13]. The intramuscular vaccine injections also have major adverse effects such as injection-related local pain $(78 \%)$, infection and infestation (52\%), gastrointestinal disorder (13.4\%), nervous system disorder $(9.4 \%)$, and reproductive and breast disorders (24.8\%) [10]. Some vaccines such as HPV 16 antigen can induce autoimmune reaction against human proteins which might lead to pathologies such as spinal muscular atrophy, proximal muscle weakness that cause waddling gait, toe-weakening, lordosis, frequent falls, difficulty in standing up and climbing stairs, cardiovascular and musculoskeletal abnormalities, disorder of lipoprotein metabolism leading to hypercholesterolemia, and increased proneness to coronary artery disease [14].

The adjuvant in the vaccine is also responsible for some adverse effects. The aluminum adjuvant in these vaccines or any other vaccine has also been shown to cause adverse effects. Stephanie Seneff has shown that children may not react acutely to the aluminum adjuvated vaccine, which can lead to neural damage that is partly mediated by exuberant production of nitric oxide [15]. Another important factor involved with adverse effect is needle size of the injection, especially for infants, children, and geriatric patients. Choosing an appropriate length and gauge of a needle may be important to ensure that a vaccine is delivered to the appropriate site and produces the maximum immune response while causing the least possible harm [16]. Many vaccines are recommended for injection into muscle (intramuscularly), although some are delivered subcutaneously (under the skin) and intradermally (into skin). It has been found that use of inappropriate size of needles can cause infant to experience local reactions such as redness, swelling, tenderness, or hardness [16].

Another common route of vaccine administration is the oral route. However, oral delivery of vaccines has several limitations. Parenteral route of administration is the only established route that overcomes all these drawbacks associated with these orally less/inefficient drugs. But these formulations are costly, have least patient compliance, require repeated administration, in addition to the other hazardous effects associated with this route [17]. In order to prompt a robust immune response, the oral delivery of antigens needs to overcome multiple physicochemical and biological barriers in the GI tract. Among them is the biological barrier of the intestinal epithelium and its mucus secreting layers which serve to digest consumed material for nutrient absorption and to 
protect the body from the invasion of pathogenic threats $[18,19]$. To accomplish these tasks, the GI tract includes a highly acidic environment in the stomach, a significant $\mathrm{pH}$ range along the length of the GI tract, and the presence of proteolytic enzymes responsible for protein degradation. These characteristics can interfere with the delivery of fragile biomolecules, such as antigenic proteins or peptides, which are highly susceptible to degradation and denaturation [20]. Furthermore, there is a temporal limitation for the absorption of these formulations due to the residence time in the small intestine $(3-4 \mathrm{~h})$, where most absorption processes occur [21].

Another major hurdle in the development of oral vaccines is that a higher dose of antigen is needed to induce an immune response when compared to traditional parenteral immunizations [22]. This characteristic limit the possible formulations used as carriers as they must be able to successfully carry the required antigen dosage. Larger doses also increase the risk of inducing tolerance instead of stimulating a protective response [23]. The GI tract is constantly exposed to a variety of pathogens. If a vaccine does not induce the appropriate danger signals, the body can recognize it as non-pathogenic and avoid triggering an immune response, resulting in immune tolerance instead of protection [24]. Thus, it is critical in the design of oral vaccine carriers to include potent adjuvants in order to sufficiently stimulate the immune system. Therefore, it is very important to develop a suitable dosage form and safe, patient compliant route of vaccine administration. An orally dissolvable vaccine formulation for buccal administration can be a great choice to address the above limitations.

\section{Current research in vaccine formulations:}

Researchers are working tirelessly to find an effective and easy way to administer and preserve vaccines with low cost and no side effects. There are many different forms of vaccines under investigations. A recent vaccine in the development stage is DNA vaccine. DNA based vaccine is a promising treatment for malignant cancer. Nano or microparticulate form of vaccines is also a new development in which multiple antigen including prophylactic and therapeutic can be included. Liposome based vaccines or particulate vaccines are the most common focus of interest as these can address all the vaccine limitations and able to elicit most effective vaccines. Virus-like particle (VLP) based vaccines are also promising vaccines for cancer treatment.

\section{DNA Based vaccines}

DNA based vaccines are new types of vaccines currently in experimental stages. DNA vaccination has emerged as a promising alternative to traditional protein-based vaccines for the induction of protective immune responses. DNA vaccines offer several advantages over traditional vaccines, including increased stability, rapid and inexpensive production, and flexibility to produce vaccines for a wide variety of infectious diseases [14]. Results from numerous clinical trials have demonstrated that DNA vaccines are well tolerated by patients and do not trigger major adverse effects. DNA vaccines are also very cost effective and can be administered repeatedly for long-term protection. Researchers have found that when the genes for a microbe's antigens are introduced into the body, some cells will take up that DNA. The DNA then instructs those cells to make the antigen molecules. The cells secrete the antigens and display them on their surfaces. The DNA vaccine couldn't cause the disease because it wouldn't contain the microbe, just copies of a few of its genes. In addition, DNA vaccines are relatively easy and inexpensive to design and produce. Despite, all of the practical advantages, DNA vaccines have limitations. Sometimes, cellular immune responses caused by DNA is reduced as a result of immune tolerance against endogenous self-antigens in tumors [15]. Delivery route plays an important role in DNA vaccine's ability to elicit the desired response. The vaccine's response varied by targeting various professional antigen presenting cells (APCs) associated with different tissues. Also, different materials are required that can meet the requirements of each route of delivery. The routes of administration that have been investigated for DNA vaccines include parenteral routes such as intramuscular, intradermal, and subcutaneous injection and mucosal routes such as oral, intranasal, and vaginal. Parenteral route administration can promote activation of tissue-specific APCs (e.g. Langerhans cells in the dermis in intradermal injection) to induce both the humoral and cellular immune responses. On the other hand, the mucosal route of vaccine administration can generate local immunity at body sites that serve as common routes of entry for many pathogens [25]. The vaccine formulation of DNA is also an important factor for immunogenicity. Thus far the naked DNA has been 
used for vaccination, however the naked DNA elicited measurable levels of antigen-specific immunity when administered intramuscularly and, in most cases, immune responses were weak [26]. The better alternate could be using micro or nanoparticulate formulation. The formulation of DNA vaccines into micro- and nanoscale particles has implications for the immunogenicity of the delivered vaccines. It has been found that particles ranging in size from 1 to $10 \mathrm{~mm}$ are the preferred platforms for targeted delivery to APCs due to their preferential uptake by APCs over other cells [27]. On the other hand, nanoparticles can directly reach the lymph nodes, have multiple routes of uptake, and often achieve an overall higher transfection efficiency when compared to microparticles [28].

\section{Liposome vaccines}

Liposome is a new biotechnological product which consists of a bilayer structure having lipophilic and hydrophilic parts. Researchers have been trying to develop a vaccine formulation using liposome as antigen carrier. Zang et al. have evaluated the formulation development using liposome and Astragalus. It was found that Astragalus saponins can be used as a valuable additive to for enhancing the effectiveness of vaccines. Such addition can stimulate the immune response significantly that can benefit tumor therapy [29]. They also have shown that when astragalus saponins, cholesterol, and liposome are incorporated into a particulate delivery system along with antigen, they are able to enhance cellular immune response to a significantly high level which can induce cytotoxic $\mathrm{T}$ lymphocytes (CTLs) against tumors [29]. De Serrano and Burkhart also have developed a liposome-based vaccine formulation which can be used for the treatment of important viral, bacterial, fungal and parasitic infections (including tuberculosis, TB) [30].

In another study, Liang et al. introduced a versatile nanovaccine of liposomes-coated gold nanocages (Lipos-AuNCs) modified with DCs specific antibody aCD11c for targeted delivery of adjuvant MPLA and melanoma antigen peptide TRP2 to promote the activation and maturation of DCs, and enhance tumor-specific immunogenicity [32]. The results demonstrated that targeted antigen/adjuvants-loaded AuNCs exhibited enhanced antitumor immune response to inhibit tumor growth and metastasis in both B16-F10 prophylactic and lung metastasis models [31]. Miao also has observed enhanced immune response to rabies viruses using liposomes as adjuvants [32]. In this study, the immune responses were compared between the mice treated with either liposome solution (LipoRV) or inactivated rabies vaccine (IRV). Higher levels of interleukin-2 $(\mathrm{p}<0.05)$, interferon- $\gamma(\mathrm{p}<0.01)$, and natural killer cell activity $(p<0.05)$ were observed in the mice immunized with LipoRV than those with IRV. The potency of LipoRV was significantly higher than that IRV $(\mathrm{p}<0.05)$. In addition, three injections of LipoRV on days 0,3 , and 14 could elicit similar RVNA levels as the five shots of IRV. The results also showed a higher survival rate in mice treated with three shots of LipoRV (56.2\%) than five shots of IRV (40.6\%). This study suggests that liposome enhances the immune response of mice to rabies vaccine and could be applied as a potential immunopotentiator [32].

Lai et al. have investigated the antitumor potential of a novel liposomal vaccine, $\mathrm{M} / \mathrm{CpG}$ ODN-TRP2-Lipo [33]. They developed a vaccination strategy by assembling the DC-targeting mannose and immune adjuvant $\mathrm{CpG}-\mathrm{ODN}$ on the surface of liposomes, which were loaded with melanoma-specific TRP2180-188 peptide as liposomal vaccine. M/CpG-ODN-TRP2-Lipo treatment was used to intendedly induce activation of DCs and antitumor- specific immune response in vivo. The results demonstrated in vitro that the prepared liposomal particles were efficiently taken up by DCs. This uptake led to an enhanced activation of DCs, as measured by the upregulation of MHC II, CD80, and CD86. Furthermore, M/CpG-ODNTRP2-Lipo effectively inhibited the growth of implanted B16 melanoma and prolonged the survival of mice. This therapy significantly reduced the number of myeloid-derived suppressor cells (MDSCs) and regulatory $\mathrm{T}$ cells, while simultaneously increasing the number of activated $\mathrm{T}$ cells, tumor antigen-specific CD8+ cytotoxic T cells, and interferon- $\gamma$-producing cells. At the same time, it was found to suppress tumor angiogenesis and tumor cell proliferation, as well as up-regulate their apoptosis. Interestingly, MyD88-knockout mice had significantly shorter median survival times compared to wild-type mice following the administration of M/CpG-ODN-TRP2-Lipo. The results suggest that the antitumor activities of the vaccine partially rely on the Myd88 signaling pathway. The results further indicate that compared to whole tumor cell lysate-based vaccine, $\mathrm{M} / \mathrm{CpG}$ ODN-TRP2-Lipo (a tumor-specific antigen peptide- 
based vaccine) improved survival of tumor-bearing mice as well as enhanced their antitumor responses [33].

Khademi et al. have studied the effect of liposome on TB subunit vaccines and found that cationic liposomes can increase the potential of different TB subunit vaccines by serving as adjuvants/delivery systems. They evaluated the potential for cationic liposomes to be used as adjuvants/delivery systems for eliciting immune responses against TB subunit vaccines. They showed that cationic liposomes have extensive applications either as adjuvants or delivery systems, to promote immune responses against Mycobacterium tuberculosis (Mtb) subunit vaccines. Cationic liposomes can provide long-term storage of subunit TB vaccines at the injection site, confer strong electrostatic interactions with APCs, potentiate both humoral and cellular (CD4 and CD8) immune responses, and induce a strong memory response by the immune system. Therefore, their results concluded that, cationic liposomes can increase the potential of different TB subunit vaccines by serving as adjuvants/delivery systems. These properties further suggested that the use of cationic liposomes can be used to produce an efficient vaccine against TB infections [34].

\section{Bilosome vaccines}

A different lipid-based carrier being explored for oral immunization is bilosome. These are non-ionic surfactant vesicles that have adjuvant functionalities which can incorporate bile salts in their formulation. Bilosomes are typically synthesized with monopalmitoyl glycerol (MPG), cholesterol (CH), and dicetyl phosphate (DCP); and surfactants such as sodium deoxycholate (SDC), or sorbitan tristearate (STS). Like liposomes, bilosomes also have a bilayer with polar and non-polar ends, which allows them to incorporate different type of vaccines. One limitation of conventional liposomal vesicles is that they are disrupted by bile salts. However, when the vesicles are fabricated in the presence of bile salts, such as in bilosomes, they are no longer affected by the bile salt action and remain stable. These systems can stimulate humoral and cellular immune responses and the inclusion of bile salts allows for the protection of the cargo from the harsh environment of the GI tract [35]. One of the main advantages of bilosomal formulations is the improved stability that they can confer to fragile antigens. A study has shown that bilosomes are able to entrap and stabilize a variety of fragile antigens, including tetanus toxoid (TT), A/Panama (influenza A immunogen), diphtheria toxoid, and Bac-VP1 (hand, foot and mouth disease vaccine candidate) [36]. Along with their use as carrier, bilosomes can also be used as adjuvant. The drug release study of bilosomes as adjuvant has been carried out using model antigens such as bovine serum albumin (BSA) and cholera toxin subunit B [37]. The results showed that when used as adjuvant, bilosome increases the immunogenicity significantly. In addition, the immunogenic abilities of bilosomes have been explored using various disease models, such as mannosylated bilosomes targeting DCs for oral immunization against hepatitis $\mathrm{B}$ virus that generated both systemic and local immunity, including mucosal immunity [38]. Bilosomes formulations have been found as very promising vaccines that have shown capabilities to stimulate balanced mucosal and systemic immunity [38]. Bilosomes are vaccine delivery systems that can use fragile antigens and elicit a long-term immunity and protection against lethal diseases.

\section{Particulate vaccines}

Particles in micron or nano size have recently been the focus of interest for vaccine delivery. Particulate form of vaccine offers several advantages. A particulate formulation has huge potential in vaccine development as the particle can be used as antigen carrier and/or adjuvant and can address the issue of adverse effects that are caused by conventional vaccines [39]. Particulate carriers can serve as an effective antigen delivery system that is able to enhance and/or facilitate the uptake of antigens by antigen-presenting cells [40,41]. Particle based antigen carriers can also serve as a depot for controlled release of antigen, thereby increasing the availability of antigen to the immune cells $[42,43]$. In addition, particle-based adjuvants possess the ability to modulate the type of induced immune responses when used alone or in combination with other immune-stimulatory compounds [44]. Particulates can protect the integrity of antigens against degradation until delivered to the immune cells as antigens must be protected from the harsh acidic conditions of the stomach and enzymatic degradation in the GI tract $[45,46]$. Another advantage of using particulate formulation of a vaccine is that it can eliminate the use of adjuvants which do not have much immunogenic effect and can cause side effects. Examples of nanoparticle-based 
vaccines include oral biodegradable microspheres with recombinant anthrax vaccine for immunization against anthrax infection, poly (DL-lactide-coglycolide (DLPLG) microspheres encapsulating phosphorylcholine against Salmonella typhimurium, and albumin-chitosan mixed matrix microspherefilled coated capsule formulation of the typhoid vaccine [47].

Monkare et al. have developed a PLGA nanoparticle-based microneedle for vaccine delivery [44]. The hyaluronan (HA)-based dissolving microneedles (MNs) are loaded with PLGA nanoparticles (NPs) co-encapsulating ovalbumin (OVA) and poly(I:C) for intradermal immunization. The NP:HA ratio used for the preparation of dissolving MNs appeared to be critical for the quality of MNs and their dissolution in ex vivo human skin [44]. Results revealed that HA-based dissolving MNs loaded with PLGA NPs were developed for minimally invasive intradermal vaccination. Inclusion of PLGA Nanoparticles in MN mediated delivery of vaccine resulted in robust humoral and cellular immune response. The results certainly set the stage for future development of $\mathrm{MN}$-based delivery of particulate vaccines.

Bhowmik et al. investigated the role of chitosan which provides a positive charge on the surface of albumin based microparticle. The results showed enhancement of the immune response of plasmid DNA (pDNA) to hepatitis-B surface antigen (HbsAg) vaccine after oral administration. The augmentation of both humoral and cellular immune responses for a prolonged period after vaccine administration was observed [49]. The addition of chitosan to the pDNA microparticle provides a positive charge on the surface which helps the particles penetrate the cell membrane and release DNA, leading to the subsequent gene expression [50].

Particle based vaccine can overcome the limitations of many antigens which are very sensitive to harsh acidic conditions or any enzymatic degradation. Also, particulate vaccine can target specific areas. The particles can be designed to fulfil any purpose. For example, along with antigen particle, the matrix can also entrap immunostimulatory cytokines such as IL-2, IL-12 which will increase the immunogenicity of the vaccine. In addition, it is possible to incorporate any ligand which is specific to the receptors of any cell or tissue. For example, Auria A L ligand can be included in the particle which is M cell specific [51].
When taken up by oral route, the antigen particles are absorbed by the $M$ cells in the Peyer's Patch area. Peyer's patch area is full of M cells which act as a gate keeper for the antigens and pass the antigens to antigen presenting cells (APCs) to initiate the antibody production process. Therefore, adding $\mathrm{M}$ cell receptor specific ligands will enhance the specific targeting and immunogenicity of the vaccine. Moreover, it is also possible to incorporate any charge on the surface of the vaccine to promote specific targeting via electrostatic interaction.

\section{Virus like particle-based vaccines}

Virus like particle (VLP) based vaccine is a new type that uses virus like particle as antigen. It contains the virus structural proteins, i.e., the capsid of the virus which has no DNA in it. VLPs are differentiate from soluble recombinant antigens by stronger protective immunogenicity associated with the VLP structure [52]. Thus, the VLPs can elicit immune response as if the immune system has been exposed to a real virus [53]. Although VLPs are the capsid of the virus, they are unable to replicate and as such are harmless and safe. They are excellent prophylactics because they are self-assembling bionanoparticles (20 to $60 \mathrm{~nm}$ in diameter) that expose multiple epitopes on their surface and faithfully mimic the native virions [54]. Another very important advantage is that VLP eliminates the limitations of virus-based vaccine. Unlike attenuated bacterial vaccines, the authentic and attenuated virions cannot be used as antigens in a prophylactic vaccine because they would contain oncogenic viral genomes that would be infectious [55]. VLPs can address this issue in developing vaccines against viral diseases. In addition, virus like particles not only resemble authentic virions morphologically, but they also mimic virions immunologically which means they are able to induce high titers of neutralizing antibodies to conformational epitopes when vaccinated [56,57]. On the surface of VLPs, there is an array of antigenic epitopes that mimics the surface of native virions more reliably than specific isolated subunits or subcomponents of the virus [56]. These characteristics provide VLPs with a significant advantage over other platforms in developing an effective antiviral vaccine. To date, there are only a few VLP-based vaccines on the market such as Engerix $B^{\circledR}$ and Recombivax $\mathrm{HB}^{\circledR}$ against the hepatitis $\mathrm{B}$ virus (HBV), and Gardasi $^{\circledR}$ and Cervarix ${ }^{\circledR}$ against the human papillomavirus (HPV). 
Several VLP based vaccines are currently under investigation. Influenza VLPs have been developed by different laboratories. Several studies have shown that influenza VLP vaccination induces protective immune responses against seasonal, pandemic, and avian influenza viruses in animal models [58]. Carter et al. reported the development and characterization of a COBRA (computationally optimized broadly reactive antigen) based vaccine for both seasonal and pandemic H1N1 influenza virus isolates using VLPs. Nine prototype H1N1 COBRA HA proteins were developed and tested in mice using a virus-like particle (VLP) format for the elicitation of broadly reactive, functional antibody responses and protection against viral challenge. The H1N1 COBRA HA VLP vaccines elicit anti-head antibody responses against a broad number of H1N1 [59].

Ebola VLPs were also developed by Carra et al. A procedure to reduce the size of filovirus VLP, which permitted the purification of "nano-VLP" using chromatography and filtration, was developed which can be used as vaccine against malignant Ebola. The nano-VLP was lyophilized without loss of GP and VLP structure and immunogenicity. It was found that lyophilized nano-VLP have greatly enhanced thermostability, suggesting that the creation of an Ebola VLP vaccine without a cold chain requirement is possible [60].

Boigard et al. investigated a VLP based Zika vaccine. The newly emerged mosquito borne Zika virus poses a major public challenge due to its ability to cause significant birth defects and neurological disorders. They describe a safe, effective and straightforward strategy to rapidly produce a Zika vaccine. VLPs are produced in mammalian cell culture suspensions offering a suitable system for rapid scale up of manufacturing without the risk of working with an infectious agent. The study concluded that the Zika VLP platform can put forward a vaccine composition and production system ready for clinical development of a safe and effective prophylactic Zika vaccine, which is greatly needed to meet the challenges imposed by the spread of the Zika epidemic [61].

\section{Quickly soluble film based buccal vaccine delivery system}

Among the various transmucosal routes, buccal mucosa is the best choice as it has excellent accessibility and is very suitable for administration of controlled release dosage forms. Additionally, buccal drug delivery has a high patient acceptability compared to other non-oral transmucosal routes of drug administration [62]. Buccal area has direct access to the systemic circulation through the internal jugular vein which allows the drug to avoid acid hydrolysis in the gastrointestinal (GI) tract and bypass hepatic first pass metabolism. Thus, avoiding the first pass effect leads to a high bioavailability of the drug and can reduce the dose amount. Moreover, rapid cellular recovery of the buccal mucosa is another advantage of this route [63]. On the other hand, the buccal route has some disadvantages in drug delivery such as low drug permeability when compared to the sublingual membrane $[64,65]$. In addition, the buccal cavity has comparatively smaller surface area; the total surface area of the oral cavity membranes that are available for drug absorption is $170 \mathrm{~cm}^{2}$, of which $\sim 50 \mathrm{~cm}^{2}$ represents nonkeratinized tissues, including the buccal membrane $[66,67]$. Another major issue with buccal administration in mouth cavity is the continuous secretion of saliva (0.5-2 1/day) which leads to subsequent dilution of the drug. Swallowing of saliva can also potentially lead to the loss of dissolved or suspended drug and, ultimately, the involuntary removal of the dosage form [68]. However, if these limitations are addressed, then the buccal route can certainly become much more effective and acceptable than the oral route of administration. In this review, we intend to evaluate the feasibility of buccal administration of vaccine in quickly soluble thin film.

Buccal drug delivery has lately become an important route of drug administration. It is interesting to note that the permeability of buccal mucosa is approximately 4-4,000 times greater than that of the skin, but less than that of the intestine [69]. An ideal fast dissolving delivery system should have the following properties: high stability, transportability, ease of handling and administration, no special packaging material or processing requirements, no water necessary for application, and a pleasant taste [69]. Although current vaccines are proven to be highly effective, they exhibit several drawbacks that need to be addressed. These drawbacks greatly inhibit the global mass use of current vaccines. Some of these drawbacks include the cost of the vaccine itself, adverse effects of injectable vaccines, the need to maintain a controlled temperature for storing the vaccines, and the need for an expert to administer the vaccines [70]. Therefore, finding an alternative vaccine formulation that will eliminate these drawbacks is becoming the focus of 
current efforts in vaccine research and development. [17].

Compared with the other mucosa, the buccal and sublingual routes are preferable because they provide better permeability of the drug [64]. The sublingual route is targeted for the delivery of drugs exhibiting high permeability across the mucosa and is utilized for the treatment of acute disorders. On the other hand, the buccal route is preferred for the treatment of chronic diseases, where an extended release of the drug is desired [71]. Direct access to the systemic circulation through the internal jugular vein is possible with buccal drug delivery [17]. Many other advantages such as oral mucosa's accessibility, excellent blood supply, avoiding the hepatic firstpass metabolism, and rapid repair and permeability profile, make the buccal and sublingual routes extremely attractive for local and systemic drug delivery [72]. In addition, administration via the oral cavity or oral mucosal route, including buccal, sublingual, and gingival mucosa, has received a great deal of attention as a novel delivery route for therapeutic drugs because it does not subject proteins and/or peptides to the degradation usually caused by gastrointestinal administration. Among oral mucosal routes, the sublingual route is commonly used for immunotherapeutic treatments of allergy because it quickly absorbs antigens and allows them to enter the bloodstream without passing through the intestine or liver, thereby eliciting allergen-specific tolerance [73]. Thus, the sublingual administration was shown to be safe and no cases of anaphylactic shock in humans have been reported so far [74]. Oral films dissolve more rapidly than other dosage forms. It is very important to address the poor stability of liquid dosage forms, especially the aqueous formulations. Unlike the thin films, there is a need for great care during accurate measurement of the amount of liquid and for shaking the bottle every time before administration, which contributes to less compliance/acceptability by patients [75]. Oral dissolving film is extremely useful for pediatric, geriatric, and psychiatric patients since it is easy to administer and it minimizes the risk of choking or suffocation, thus ensuring patient safety [76]. Oral films can also be beneficial for bedridden and noncooperative patients as they can be administered easily with hardly any risk of patients spitting them out. The rate of disintegration of an oral film is rapid, allowing the drug to be released quickly prior to oromucosal absorption. Many drugs that undergo degradation in the GI tract are being administered employing oral films [77]. The film dosage form of a vaccine can elicits both antibody mediated (preventative) and cell mediated (activates t-cells to destroy virus) mechanisms. Film dosage forms can be used to prepare vaccines for administration via the mouth cavity, GI mediated, and vaginal routes [78]. The current marketed quickly dissolvable film dosage forms are listed in the table 2.

A multilayered film can be designed to deliver vaccines. These can be two or three layered, each having its own function and structure. In three layered film form, the inner layer can be mucoadhesive which helps the film to be stick to the buccal and sublingual area. It can also contain permeability enhancing agent. The middle layer contains the vaccines. And the outer layer function is to force the vaccine to move to one direction and inhibit its dissolution in the saliva. The film of this layer should dissolve slowly compare with the other two layers. On the other hand, in two layered film dosage form, the mucoadhesive layer will containing the vaccine so that one extra layer is not needed. This layer will also contain the permeation enhancing agent. The outer layer will contain the polymer that dissolves slowly and protect the vaccines from mixing or dissolving in saliva. The films are shown in following Figure 1.

Currently, not many film dosage forms of drugs are available on the market. However, there are some vaccines in film dosage forms that are being developed. These vaccines include measles vaccine, live bacterial typhoid fever vaccine, salmonella vaccine, diphtheria toxoid vaccine, tetanus toxoid vaccine, poliomyelitis vaccine, rotavirus vaccine [79-81], and 9-valent pneumococcal conjugate vaccine [82]. The rotavirus vaccine is designed to melt quickly in a baby/child's mouth, prompting the baby/child to swallow the vaccine $[79,80]$. The dissolved medication is coated with a material to protect it in the child's stomach, and it is designed to release the vaccine in the small intestine where it should trigger an immune response to prevent a rotavirus infection [81]. Quickly soluble film dosage forms can also be used as therapeutic vaccines for local administration. One unique example could be a film dosage form for the HPV vaccine which can be used in the cervix area to create a localized effect. 


\begin{tabular}{|c|c|c|c|c|}
\hline Product Name & Manufacturer & $\begin{array}{l}\text { Active Product } \\
\text { Ingredient (API) }\end{array}$ & Dosage form & $\begin{array}{l}\text { Use of the } \\
\text { Product }\end{array}$ \\
\hline Listerine & Pfizer & Cool mint & Film strip & Mouth Freshener \\
\hline Benadryl & Pfizer & Diphenylhydramine HCL & Film strip & Antiallergic \\
\hline Orajel & Del & Menthol/Pectin & Film strip & Mouth Ulcer \\
\hline Theraflu & Novartis & Dextromethorphan HBR & Thin Film strip & Cough suppressant \\
\hline Theraflu & Novartis & Diphenylhydramine $\mathrm{HCl}$ & Thin Film strip & Cough suppressant \\
\hline Theraflu & Novartis & $\begin{array}{l}\text { Phenylephrine } \mathrm{HCl} / \\
\text { Dextromethorphan } \mathrm{HBR}\end{array}$ & Thin Film strip & Cough suppressant \\
\hline Theraflu & Novartis & $\begin{array}{l}\text { Phenylephrine } \\
\mathrm{HCl} / \text { Diphenylhydramine } \\
\mathrm{HCl}\end{array}$ & Thin Film strip & Cough suppressant \\
\hline Sudafed PE & $\begin{array}{l}\text { Wolters Kluwer } \\
\text { Health Inc. }\end{array}$ & Phenylephrine & Film strip & $\begin{array}{l}\text { Relieving } \\
\text { Congestion }\end{array}$ \\
\hline Triaminic & Novartis & Dextromethorphan HBR & Thin Film strip & Antiallergic \\
\hline Triaminic & Novartis & Diphenylhydramine $\mathrm{HCl}$ & Thin Film strip & Antiallergic \\
\hline Triaminic & Novartis & $\begin{array}{l}\text { Phenylephrine } \mathrm{HCl} / \\
\text { Dextromethorphan } \mathrm{HBR}\end{array}$ & Thin Film strip & Antiallergic \\
\hline Triaminic & Novartis & $\begin{array}{l}\text { Phenylephrine } \\
\mathrm{HCl} / \text { Diphenylhydramine } \\
\mathrm{HCl}\end{array}$ & Thin Film strip & Antiallergic \\
\hline Chloraseptic & Prestige & Benzocaine/menthol & Film strip & Sore throat \\
\hline Klonopin Wafers & $\begin{array}{l}\text { Solvay } \\
\text { Pharmaceuticals }\end{array}$ & Clonazepam & Wafer & $\begin{array}{l}\text { Treatment of } \\
\text { Anxiety }\end{array}$ \\
\hline Suppress & InnoZen Inc. & Menthol & Film & $\begin{array}{l}\text { Cough } \\
\text { Suppressant }\end{array}$ \\
\hline Gas-X & Novartis & Simethicone & Film & Anti Flatuating \\
\hline Zuplenz & Galena Biopharma & Ondansetron & Film & $\begin{array}{l}\text { Nausea and } \\
\text { vomiting }\end{array}$ \\
\hline Zofran & GSK & Ondansetron & Film & $\begin{array}{l}\text { Nausea and } \\
\text { vomiting }\end{array}$ \\
\hline
\end{tabular}

The possibility of using different types of vaccine in film dosage form as a delivery system needs to be evaluated. Live vaccine in film dosage form will not be a good choice as size, permeability, and regeneration of antigen may cause adverse effects. Live attenuated influenza virus (A/PR/8 strain, H1N1) has been tested for administration via the sublingual route and has been found to be safe and effective for inducing protective immune responses in both mucosal and systemic compartments [83]. In an in vivo mice study, Song et al. have shown that administration of influenza vaccine produced virus-specific IgG in the serum and secretory $\operatorname{IgA}(\operatorname{sg} \mathrm{A})$ in the respiratory mucosa. A single sublingual dose of $\mathrm{A} / \mathrm{PR} / 8$ virus prevented lung pathology induced by influenza virus challenge and provided a broad-range cross-protection against different influenza virus subtypes. Thereby, the risk of potential passage of vaccine virus to the olfactory bulb was avoided by using the sublingual route since no viral RNA was detected in brains of sublingually vaccinated mice, in contrast to mice that received the same vaccine intranasally [84]. Therefore, it is possible for vaccine administration in film dosage form via the sublingual route to elicit a protective immune response in both mucosal and systemic compartments when appropriate adjuvants and other auxiliary materials are used along with the vaccines. One approach to widening the choice of vaccine types without the use of live-attenuated microorganisms is the development of adjuvants and delivery systems. These have recently been reviewed under the categories of mineral salts, oil-in-water emulsions, microbial derivatives, natural products, endogenous immunostimulatory factors, inert vehicles, and lipid particulates [85]. Some of these are more appropriate in mucosal delivery for directly targeting the mucosal immune system (MIS). For example, alum, which is used in many parenteral vaccines, does not induce mucosal immunity. 
Delivery systems can also be used in combination with adjuvants and are designed to increase delivery, targeting, protection against degradation and controlled release of antigen at a particular site. The use of polymeric carriers such as chitosan, poly(lactic-co-glycolic acid) (PLGA) and poly lactic acid (PLA) have shown success as adjuvants and have been used as delivery carriers for vaccines in the form of microparticles and nanoparticles [86]. Reported use of PLGA include spray-dried nanoparticles as carriers for diphtheria CRM-197 antigen and recombinant hepatitis B surface antigen, spray-dried microparticles containing recombinant antigen $85 \mathrm{~B}$ against $\mathrm{TB}$, and wet microspheres containing hepatitis B surface antigen $[87,88,89]$.

Sun and Xia have listed several mechanisms of immune responses that can be initiated by nanomaterial and are related to several factors such as depot effect, NLRP3 inflammasome activation, perturbation of DCs membrane, autophagic regulation, lymph node targeting, toll-like receptor signaling, B cell activation, $\mathrm{T}$ cell differentiation, antigen presentation, host DNA release, and soluble mediators [88]. In addition, nanomaterial increases cellular uptake of vaccines. Due to their small size and high surface area, nanoparticles can interact easily with biomolecules both at the surface and inside cells. Another example of nano particle vaccine is NanoNiccine which is a hybrid nanoparticle based vaccine studied by $\mathrm{Yun} \mathrm{Hu}$ et al. NanoNiccine was composed of a poly(lactide-coglycolide) acid (PLGA) core, keyhole limpet hemocyanin (KLH) as an adjuvant protein enclosed within the PLGA core, a lipid layer, and nicotine haptens conjugated to the outer surface of the lipid layer. Unlike conventional nicotine vaccine, NanoNiccine is not a nicotine-protein conjugate vaccine. The cellular uptake study demonstrated that NanoNiccine was ideal for internalization and processing by dendritic cells (DCs).

A.

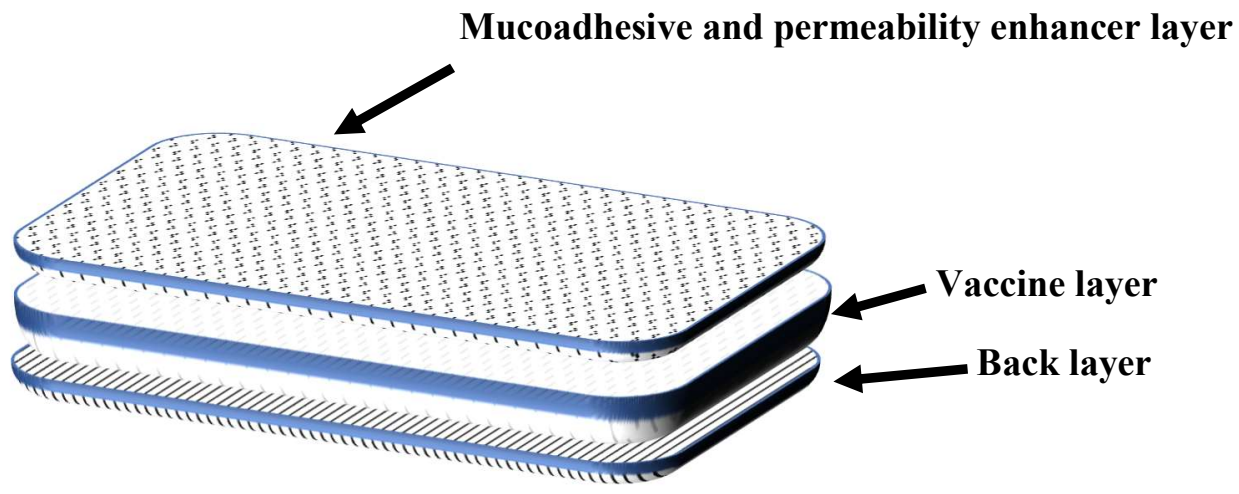

B.

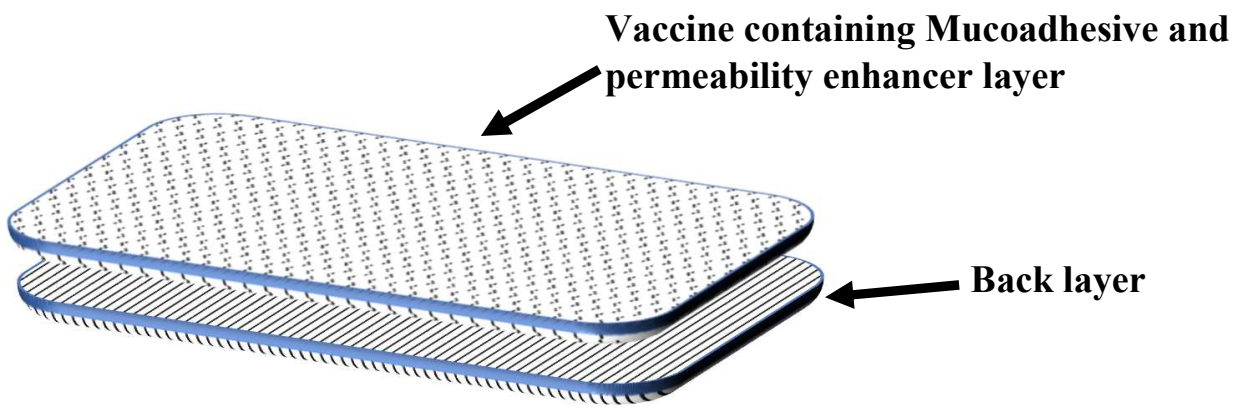

Figure 1: Multilayered film dosage forms, A. Triple layered film with vaccine layer in the middle (top), B. Double layered film with vaccines in mucoadhesive layer (bottom). 
In the animal study with mice immunization, NanoNiccine showed up to a $400 \%$ higher titer of anti-nicotine IgG than the positive control, Nic$\mathrm{KLH}$. The results suggest that the immune response induced by NanoNiccine was antibody response dominant and was found to be safe in mice [89]. In another nano-particle based vaccine study, Bharali et al. studied the nano-particulate delivery system of hepatitis B vaccine. They described the use of methoxypolyethylene glycol-poly(lactide-coglycolide) nanoparticles as a delivery system for recombinant hepatitis B surface antigen (HBsAg). The in vitro cell study showed efficient uptake of the nanoparticle vaccine which was visualized by confocal imaging system. In the animal study of the nanoparticle based vaccine, anti-HBs antibodies were detected at significantly earlier time points than in mice immunized with the nonencapsulated recombinant vaccine. [90].

Nanomaterial enhances the targeting of vaccines. Nanoparticles have some good properties such as tropism of lymphatic system, passive targeting (easy to be engulfed by macrophages as foreign bodies), active targeting (by modification) and physical targeting (by encapsulating magnetic material). Nanoparticles can be used as a carrier to distribute the drug and target only diseased tissues/cells, which avoids any effects on normal tissues/cells. The ideal design is to insert antibodies on the surface of nanoparticles that can bind to membrane proteins of specific cancer cells, allowing the nanoparticles to act as 'missiles' [91].

Nanomaterial increases permeability and efficacy of drugs passing through biological barriers. In a review article by Capron et al., three types of biological barriers such as mucosal barrier, skin barrier and blood-brain barrier (BBB) were discussed. Nanomaterial can improve permeability of the drug in order to overcome these barriers. With respect to the mucosal barrier, nanoparticles can prolong the retention time of gastrointestinal tract, synchronously avoiding destruction of the drug by the harsh environment of enzymes and sequentially improving absorption of the drug by electrostatic interactions, hydrophobic interactions, and polymer chain interactions [92].

Barros et al. also reported a novel delivery system of laminated polymer-based film formulation for enteric delivery of live bacterial vaccine. The experiment showed that a polymer film laminate (PFL) made from blended polymer films completely released low-molecular-weight dye under intestinal conditions ( $\mathrm{pH} 7.0)$ but failed to release live bacterial cells. In contrast, when the polymers were made from Eudragit alone, they successfully protected dried probiotic or vaccine live bacterial cells from SGF for the period of two hours and eventually released all viable cells within $60 \mathrm{~min}$ of transfer into simulated intestinal fluid. A great advantage of polymer film-based vaccine is that release kinetic can be controlled as needed [93].

\section{Future direction of film dosage form vaccine for buccal administration}

The buccal area can be an attractive site for the delivery of vaccine because of its accessibility, avoidance of the first pass effect, and immunological advantages over other mucosal routes of administration. Film dosage forms for buccal administration dissolve at the first contact with saliva in mouth cavity and facilitate the coating of the buccal surface, enhancing the delivery of the vaccine into the buccal mucosae. These films also assure dosing accuracy and elicit the induction of an effective immune response. Buccal mucosae is rich in immune cells such as dendritic cells and langerhans cells which make it a suitable site for vaccine administration [93]. These cells are able to uptake vaccines in original form or particulate form from films designed for buccal delivery. Any type of vaccine can be formulated for buccal administration by optimizing the formulation in terms of type of antigen, size, surface charge, and specific receptor ligands. Particulate formulation of the vaccine (instead of the pure form) is most preferable in order to avoid the degradation of antigen by saliva. Several vaccines are currently under investigation for administration via the buccal mucosa using orally quickly dissolvable film. In addition, sublingual vaccine delivery has recently gained significant attention and numerous pre-clinical studies have been reported over the last few years.

In this article, we attempted to review the feasibility and suitability of a vaccine film form for buccal administration. Among conventional dosage forms, live vaccines in their original form are probably not suitable for use in film dosage form as they are required to have adjuvant. However, if the particle is formulated to include the adjuvant, then it would be possible to prepare a live vaccine formulation for buccal administration. In addition, subunit or conjugated vaccines, which are currently administered IM or SQ, can also be formulated in film dosage form. Gala et al. have conducted a 
preclinical study in juvenile pigs evaluating the physicochemical properties of buccal mucosal vaccine. An orally disintegrating film (ODF) containing a microparticulate measles vaccine was formulated by spray drying for buccal delivery. The results showed that the particulate vaccine significantly increased the antigen presentation and co-stimulatory molecules expression on antigen presenting cells, which is a prerequisite for Th1 and Th2 immune responses. The study results in juvenile pigs also suggested that the ODF measles vaccine formulation is a viable dosage form for noninvasive immunization that may increase patient compliance and commercial distribution [93]. Likewise, it is possible that an attenuated vaccine can be delivered via a film dosage form. New types of vaccines, such as a DNA vaccine, are also highly suitable for a film dosage form. Plasmid pDNA administration in the oral cavity of mice has been studied. After delivering the plasmid DNA, the immune responses of IgA and $\mathrm{IgG}$, as well as cell-mediated immune responses, were investigated in mice. The study revealed that intraoral administration of DNA in the cheek, using a jet immunization technique, elicited the highest IgA mucosal responses. Intranasal immunization produced strong mucosal $\operatorname{IgA}$ responses and persistent systemic IgG. The study also showed that the intraoral administration of the DNA vaccine using jet injection technique has the advantage of being a simple and rapid way to administer DNA in solution and elicit specific mucosal IgA [94].

Other than the above mentioned two vaccines, a significant number of vaccines are in preclinical stages of development. In a review article by Heleen et al., about 48 vaccines were reported to be in preclinical research phase for administration via the buccal route [78]. However, all these vaccines are in liquid dosage forms which may result in significant degradation by saliva. Therefore, formulating such vaccines in a particulate film dosage form would make them more effective and highly desirable. Overall research results of vaccine formulation development for buccal administration and the parallel development of quickly soluble oral films have undoubtedly been very encouraging; they certainly promise to change the future of vaccine delivery.

\section{CONCLUSION}

Vaccines have significantly decreased the morbidity and mortality associated with many diseases. Despite these successes, shortfalls in vaccination rates still exist and more needs to be done to avert needless vaccine-preventable diseases and deaths. Based on our review of the preparation, characterization, efficacy, size, and permeability, it is possible for most vaccines to be delivered in film dosage forms via the buccal route. Vaccines in film dosage forms are more patient compliant, more potent, less expensive, and can produce a greater immune response. Future directions of the buccal administration of vaccines in film dosage forms lie in vaccine formulation development.

\section{REFERENCES}

1. Bala R, Pawar P, Khanna S, et al. Orally dissolving strips: A new approach to oral drug delivery system. Int J Pharm Investigation. 2013;3(2):67.

2. Office of Disease Prevention and Health Promotion. Immunization and Infectious Diseases. https:/www.healthypeople.gov/2020/topicsobjectives/topic/immunization-and-infectiousdiseases.

3. Centers for Disease Control and Prevention. Ten great public health achievements--United States, 1900-1999. MMWR. Morbidity and mortality weekly report 1999;48.12: 241.

4. Anselmo AC, Gokarn Y, Mitragotri S. Noninvasive delivery strategies for biologics. Nature Reviews Drug Discovery. 2019;18: 19-40.

5. Brandtzaeg P. Function of mucosa-associated lymphoid tissue in antibody formation. Immunol Invest. 2010;39(4-5):303-355.

6. Amorij JP, Kersten GF, Saluja V, et al. Towards tailored vaccine delivery: needs, challenges and perspectives. J Control Release. 2012;161(2):363376.

7. U.S. Department of Health and Human Services. https://www.vaccines.gov/basics/types/index.html.

8. National Institute of Allergy and Infectious Diseases.

https://www.niaid.nih.gov/research/vaccine-types.

9. World Health Organization. Vaccine Safety Basics. Module 2: Types of Vaccine and Adverse reactions - Route of Administration; http://vaccine-safetytraining.org/route-of-administration.html

10. Trindade ES, Safety profile of human papillomavirus vaccines. Rev Bras Patol Trato Genit Infer. 2012;2: 76-80.

11. Kang S, Kim KH, Kim YT, et al. Safety and immunogenicity of a vaccine targeting human papillomavirus types $6,11,16$ and 18: a randomized, placebo-controlled trial in 176 Korean subjects. Int J Gynecol Cancer. 2008;18(5):10131019. 
12. American Academy of Allergy Asthma \& Immunology. What is the risk of Anaphylaxis after vaccination in children and adults? https://www.aaaai.org/global/latest-researchsummaries/Current-JACI-Research/What-is-therisk-of-anaphylaxis-after-vaccination

13. Uddin MN. Progress in Human Papillomavirus (HPV) Vaccine Development. J Develop Drugs. 2013;2: 122.

14. Farris E, Brown DM, Ramer-Tait AE, Pannier AK. Micro-and nanoparticulates for DNA vaccine delivery. Exp Biol Med. 2016;241(9):919-929.

15. Yang B, Jeang J, Yang A. DNA vaccine for cancer immunotherapy. Hum Vaccin Immunother. 2014;10(11):3153-3164.

16. Beirne PV, Hennessy S, Cadogan SL, et al. Needle size for vaccination procedures in children and adolescents. Cochrane Database Syst Rev. 2015; 18(6); 11-20.

17. Sudhakar Y, Kuotsu K, Bandyopadhyay AK. Buccal bioadhesive drug delivery - a promising option for orally less efficient drugs. J Control Release. 2006;114(1):15-40.

18. Pelaseyed T, Bergström JH, Gustafsson JK, et al. The mucus and mucins of the goblet cells and enterocytes provide the first defense line of the gastrointestinal tract and interact with the immune system. Immunol Rev. 2014;260(1):8-20.

19. Ensign LM, Cone R, Hanes J. Oral drug delivery with polymeric nanoparticles: the gastrointestinal mucus barriers. Adv Drug Del Rev. 2012;64(6):557-570.

20. Raza F, Zafar H, Zhu Y, Ren Y, Ullah A, Khan AU. A review on recent advances in stabilizing peptides/proteins upon fabrication in hydrogels from biodegradable polymers. Pharmaceutics. 2018;10: 1-21.

21. John B. Leiper; Fate of ingested fluids: factors affecting gastric emptying and intestinal absorption of beverages in humans, Nutrition Reviews. 2015: 73(2), 57-72.

22. Zhang L, Wang W, Wang S. Effect of vaccine administration modality on immunogenicity and efficacy. Expert Rev Vaccines. 2015;14(11):150923.

23. Vela Ramirez JE, Sharpe LA, Peppas NA. Current state and challenges in developing oral vaccines. Adv Drug Deliv Rev. 2017;114: 116-131.

24. Janeway CA, Travers $\mathrm{P}$, Walport $\mathrm{M}$, et al. Immunobiology: the immune system in health and disease. New York: Garland Pub.; 2001. https://www.ncbi.nlm.nih.gov/books/NBK27169/

25. Chen K, Cerutti A. Vaccination strategies to promote mucosal antibody responses. Immunity. 2010;33(4):479-491.
26. Nguyen DN, Green JJ, Chan JM, et al. Polymeric materials for gene delivery and DNA vaccination. Adv Mater 2009; 21:847-867.

27. O'Hagan DT, Singh M, Ulmer JB. Microparticles for the delivery of DNA vaccines. Immunol Rev 2004; 199: 191-200.

28. Prabha S, Zhou W-Z, Panyam J, et al. Sizedependency of nanoparticle-mediated gene transfection: studies with fractionated nanoparticles. Int J Pharm 2002; 244:105-115.

29. Zhang XP, Li YD, Luo LL, et al. Astragalus saponins and liposome constitute an efficacious adjuvant formulation for cancer vaccines. Cancer Biother Radiopharm. 2018;33(1):25-31.

30. De Serrano LO, Burkhart DJ. Liposomal vaccine formulations as prophylactic agents: design considerations for modern vaccines. J Nanobiotechnology. 2017;15(1):83.

31. Liang R, Xie J, Li J, et al. Liposomes-coated gold nanocages with antigens and adjuvants targeted delivery to dendritic cells for enhancing antitumor immune response. Biomaterials. 2017;149: 41-50.

32. Miao L, Yang Y, Yan M, Li Y, Zhao J, Guo J, Zheng D. Enhanced Immune Response to Rabies Viruses by the Use of a Liposome Adjuvant in Vaccines. Viral Immunol. 2017;30(10):727-733.

33. Lai C, Duan S, Ye F, et al. The enhanced antitumorspecific immune response with mannose-and $\mathrm{CpG}$ ODN-coated liposomes delivering TRP2 peptide. Theranostics. 2018;8(6):1723.

34. Khademi F, Taheri RA, Momtazi-Borojeni AA, Farnoosh G, Johnston TP, Sahebkar A. Potential of Cationic Liposomes as Adjuvants/Delivery Systems for Tuberculosis Subunit Vaccines. Rev Physiol, Biochem Pharmacol. 2018;175: 47-69.

35. Uddin MN, Kouzi SA, Hussain MD. Strategies for developing oral vaccines for human papillomavirus (HPV) induced cancer using nanoparticle mediated delivery system. J Pharm Pharm Sci. 2015;18(2):220-234.

36. Reddy ST, Rehor A, Schmoekel HG, et al. In vivo targeting of dendritic cells in lymph nodes with poly(propylene sulfide) nanoparticles. J Control Release. 2006;112(1):26-34.

37. Walter E, Dreher D, Kok M, et al. Hydrophilic poly(D,L-lactide-co-glycolide) microspheres for the delivery of DNA to human-derived macrophages and dendritic cells. J Control Release. 2001;76 (1-2):149-168.

38. Rice-Fichte AC, Arenas-Gambia AM, KahlMcDonagh MM, et al. Polymeric particles in vaccine delivery. Reviews particle-based properties, such as surface chemistry and sizes that will affect antigen presentation and processing by APCs. Curr Opin Microbiol 2009; 13(1):106-112.

39. Thomasin C, Corradin G, Men Y, et al. Tetanus toxoid and synthetic malaria antigen containing 
poly(lactide)/poly(lactide-coglycolide)

microspheres: importance of polymer degradation and antigen release for immune response. J Control Release. 1996; 41(1-2):131-145.

40. Mallapragada SK, Narasimhan B. Immunomodulatory biomaterials. Int $\mathrm{J}$ Pharm 2008; 364(2):265-271.

41. Slütter B, Soema PC, Ding Z, et al. Conjugation of ovalbumin to trimethyl chitosan improves immunogenicity of the antigen. J Control Release. 2010;143(2):207-214.

42. O'Hagan DT. Microparticles and polymers for the mucosal delivery of vaccines. Adv Drug Deliv Rev 1998; 34(2-3):305-320.

43. Hamdy S, Haddadi A, Hung RW, et al. Targeting dendritic cells with nano-particulate PLGA cancer vaccine formulations. Adv Drug Deliv Rev. 2011; 63(10-11):943-955.

44. Mönkäre J, Pontier M, van Kampen EE, et al. Development of PLGA nanoparticle loaded dissolving microneedles and comparison with hollow microneedles in intradermal vaccine delivery. Eur J Pharm Biopharm. 2018;129: 111121.

45. Bhowmik T, D'Souza B, Uddin MN, et al. Oral delivery of microparticles containing plasmid DNA encoding hepatitis-B surface antigen. J Drug Target. 2012;20(4):364-371.

46. Bielinska AU, Kukowska-Latallo JF, Baker Jr JR. The interaction of plasmid DNA with polyamidoamine dendrimers: mechanism of complex formation and analysis of alterations induced in nuclease sensitivity and transcriptional activity of the complexed DNA. Biochim Biophys Acta. 1997;1353(2):180-190.

47. Uddin MN. Virus-Like Particle: The Next Generation Vaccine? J Develop Drugs. 2014;3: 1

48. Roldao A, Mellado MC, Castilho LR, et al. Viruslike particles in vaccine development. Exp Rev Vaccine. 2010;9(10):1149-1176.

49. Zhao Q, Li S, Yu H, et al. Virus-like particle-based human vaccines: quality assessment based on structural and functional properties. Trends Biotechnol. 2013;31(11):654-663.

50. Schiller JT, Hidesheim A. Developing HPV viruslike particle vaccines to prevent cervical cancer: a progress report. J Clin Virol. 2000;19(1-2):67-74.

51. Frey A, Neutra MR. Targeting of mucosal vaccines to Peyer's patch $M$ cells. Behring Inst Mitt. 1997;98: 376-389.

52. Kirnbauer R, Booy F, Cheng $\mathrm{N}$, et al. Papillomavirus L1 major capsid protein selfassembles into virus-like particles that are highly immunogenic. Proc Natl Acad Sci U S A. 1992;89(24):12180-12184.

53. Rose RC, Reichman RC, Bonnez W. Human papillomavirus (HPV) type 11 recombinant virus- like particles induce the formation of neutralizing antibodies and detect HPV-specific antibodies in human sera. J Gen Virol. 1994;75(8):2075-2079.

54. Quan FS, Lee YT, Kim KH, et al. Progress in developing virus-like particle influenza vaccines. Exp Rev Vaccine. 2016;15(10):1281-1293.

55. Carter DM, Darby CA, Lefoley BC. Design and characterization of a computationally optimized broadly reactive hemagglutinin vaccine for H1N1 influenza viruses. J Virol. 2016;90(9):4720-4734.

56. Carra JH, Martins KA, Schokman RD. A thermostable, chromatographically purified Ebola nano-VLP vaccine. J Transl Med. 2015;13(1):228.

57. Boigard H, Alimova A, Martin GR. Zika virus-like particle (VLP) based vaccine. PLoS Negl Trop Dis. 2017;11(5).

58. Reddy PC, Chaitanya KS, Rao YM. A review on bioadhesive buccal drug delivery systems: current status of formulation and evaluation methods. Daru. 2011;19(6):385.

59. Shojaei AH, Chang RK, Guo X. Systemic drug delivery via the buccal mucosal route. J Pharm Technol. 2001; 25(6):70-81.

60. Rojanasakul Y, Wang LY, Bhat M, et al. The transport barrier of epithelia: a comparative study on membrane permeability and charge selectivity in the rabbit. Pharm Res. 1992; 9:1029-1034.

61. Collins LMC, Dawes C. The surface area of the adult human mouth and thickness of the salivary film covering the teeth and oral mucosa. J Dent Res. 1987; 66:1300-1302.

62. Lee JW, Park JH, Robinson JR. Bioadhesive-based dosage forms: the next generation. J Pharm Sci. 2000; 89:850-866.

63. Alur HH, Johnston TP, Mitra AK. Peptides and Proteins: Buccal Absorption. Swarbrick J, Boylan J.C, ed. Encyclopedia of Pharmaceutical Technology vol. 20 (3), Marcel Dekker Inc., New York, 2001, 193-218.

64. Gandhi RB, Robinson JR. Oral cavity as a site for bioadhesive drug delivery. Adv Drug Del Rev. 1994;13(1-2):43-74.

65. Galey WR, Lonsdale HK, Nacht S. The in vitro permeability of skin and buccal mucosa to selected drugs and tritiated water. J Invest Dermatol. 1976; 67:713-717.

66. Kildsgaard J, Brimnes J, Jacobi H, et al. Sublingual immunotherapy in sensitized mice. Ann Allergy Asthma Immunol. 2007;98(4):366-372.

67. Agostinis F, Tellarini L, Canonica GW, et al. Safety of sublingual immunotherapy with a monomeric allergoid in very young children. Allergy. 2005;60(1):133.

68. de Barros JM, Costabile A, Charalampopoulos D, et al. Evaluating and optimizing oral formulations of live bacterial vaccines using a gastro-small 
intestine model. Eur J Pharm Biopharm. 2016; 102:115-22.

69. Gala RP, Popescu C, Knipp GT, et al. Physicochemical and Preclinical Evaluation of a Novel Buccal Measles Vaccine. AAPS PharmSciTech. 2017;18(2):283-292.

70. Uddin MN. Alternative Vaccine Strategies for Cervical Cancer. J Develop Drugs. 2015; 4:2.

71. Hao J, Heng PW. Buccal delivery systems. Drug Dev Ind Pharmacy. 2003;29(8):821-832.

72. Hearnden V, Sankar V, Hull K, et al. New developments and opportunities in oral mucosal drug delivery for local and systemic disease. Adv Drug Del Rev. 2012;64(1):16-28.

73. Harde H, Agrawal AK, Jain S. Tetanus toxoidloaded layer-by-layer nanoassemblies for efficient systemic, mucosal, and cellular immunostimulatory response following oral administration. Drug Deliv Transl Res. 2015;5(5):498-510.

74. Stephen R. Boden1 and A. Wesley Burks. Anaphylaxis: a history with emphasis on food allergy. Immunol Rev. 2011. 242(1): 247-257.

75. Borges AF, Silva C, Coelho JF, et al. Oral films: current status and future perspectives: I-galenical development and quality attributes. J Control Release. 2015;206: 1-9.

76. Amin PM, Gangurde AB, Alai PV. Oral film technology: challenges and future scope for pharmaceutical industry. Int J Pharm Pharm Res. 2015;3(3):184-203.

77. Haque SE, Sheela A. Development of polymerbound fast-dissolving metformin buccal film with disintegrants. Int J Nanomed. 2015;10(Suppl 1): 199 .

78. Kraan H, Vrieling H, Czerkinsky C, et al. Buccal and sublingual vaccine delivery. J Control Release. 2014;190: 580-592.

79. Song JH, Nguyen HH, Cuburu N, et al. Sublingual vaccination with influenza virus protects mice against lethal viral infection. Proceedings of the National Academy of Sciences. 2008 Feb 5;105(5):1644-9.

80. Ferro V. Novel Approaches to Vaccine Research: Kerala (India). Research Signpost; 2011. Adjuvants and vaccine delivery systems; p. 199222.

81. Thomas C, Rawat A, Hope-Weeks L, et al. Aerosolized PLA and PLGA nanoparticles enhance humoral, mucosal and cytokine responses to hepatitis B vaccine. Mol Pharm. 2011;8(2):405415.

82. Madhi SA, Kuwanda L, Cutland C, Klugman KP. The impact of a 9-valent pneumococcal conjugate vaccine on the public health burden of pneumonia in HIV-infected and -uninfected children. Clin Infect Dis. 2005;40(10):1511-8.
83. Lu D, Garcia-Contreras L, Muttil $\mathrm{P}$, et al. Pulmonary immunization using antigen 85-B polymeric microparticles to boost tuberculosis immunity. AAPS J. 2010;12(3):338-347.

84. Muttil P, Prego C, Garcia-Contreras L, et al. Immunization of guinea pigs with novel hepatitis $\mathrm{B}$ antigen as nanoparticle aggregate powders administered by the pulmonary route. AAPS J. 2010;12(3):330-337.

85. Thomas C, Gupta V, Ahsan F. Particle size influences the immune response produced by hepatitis B vaccine formulated in inhalable particles. Pharm Res. 2010;27(5):905-919.

86. Ahmed TA, Aljaeid BM. Preparation, characterization, and potential application of chitosan, chitosan derivatives, and chitosan metal nanoparticles in pharmaceutical drug delivery. Drug Des Devel Ther. 2016;10: 483.

87. C Dinda S, Pattnaik G. Nanobiotechnology-based drug delivery in brain targeting. Curr Pharm Biotechnol. 2013;14(15):1264-1274.

88. Sun B, Xia T. Nanomaterial-based vaccine adjuvants. J Mater Chem B. 2016;4(33):54965509.

89. $\mathrm{Hu} \mathrm{Y}$, Hoerle R, Ehrich M, et al. Engineering the lipid layer of lipid-PLGA hybrid nanoparticles for enhanced in vitro cellular uptake and improved stability. Acta Biomater. 2015;28: 149-159.

90. Bharali DJ, Pradhan V, Elkin G, et al. Novel nanoparticles for the delivery of recombinant hepatitis B vaccine. Nanomedicine. 2008;4(4):311317.

91. Wang J, Hu X, Xianga D, Nanoparticle drug delivery systems: an excellent carrier for tumor peptide vaccines. Drug Deliv. 2018; 25(1): 13191327.

92. Capron A, Riveau G, Grzych J-M, Boulanger D, et al. Development of a vaccine strategy against human and bovine schistosomiasis: background and update. Trop Geogr Med. 1994; 46:242-246.

93. de Barros JM, Scherer T, Charalampopoulos D, et al. A laminated polymer film formulation for enteric delivery of live vaccine and probiotic bacteria. J Pharm Sci. 2014;103(7):2022-2032.

94. Lundholm P, Asakura Y, Hinkula J, et al. Induction of mucosal IgA by a novel jet delivery technique for HIV-1 DNA. Vaccine. 1999;17(15-16):20362042.

95. Merck Sharp \& Dohme Corp. M-M-R®II [package insert]. U.S. Food and Drug Administration website. www.fda.gov/media/75191/download. Accessed July 29, 2019.

96. Merck Sharp \& Dohme Corp. Varivax [package insert]. U.S. Food and Drug Administration website. www.fda.gov/media/119865/download. Accessed July 29, 2019. 
97. Merck Sharp \& Dohme Corp. Zostavax [package insert]. U.S. Food and Drug Administration website. www.fda.gov/media/119879/download. Accessed July 29, 2019.

98. Sanofi Pasteur. YF-Vax [package insert]. U.S. Food and Drug Administration website. www.fda.gov/media/76015/download. Accessed July 29, 2019.

99. PaxVax Bermuda. Vaxchora [package insert]. U.S. Food and Drug Administration website. www.fda.gov/media/98688/download. Accessed July 29, 2019.

100. GlaxoSmithKline Biologicals. Rotarix [package insert]. U.S. Food and Drug Administration website. www.fda.gov/media/75726/download. Accessed July 29, 2019.

101. Sanofi Pasteur. IPOL[package insert]. U.S. Food and Drug Administration website. www.fda.gov/media/75695/download. Accessed July 29, 2019.

102. GlaxoSmithKline Biologicals. Havrix [package insert]. U.S. Food and Drug Administration website. www.fda.gov/media/119388/download. Accessed July 29, 2019.

103. Sanofi Pasteur. IMOVAX Rabies [package insert]. U.S. Food and Drug Administration website. www.fda.gov/media/75709/download. Accessed July 29, 2019.
104. Merck and Co. Liquid PedvaxHIB [package insert]. U.S. Food and Drug Administration website. www.fda.gov/media/80438/download. Accessed July 29, 2019.

105. Sanofi Pasteur. ActHIB [package insert]. U.S. Food and Drug Administration website. www.fda.gov/media/74395/download. Accessed July 29, 2019.

106. GlaxoSmithKline Biologicals. Infanrix [package insert]. U.S. Food and Drug Administration website. www.fda.gov/media/75157/download. Accessed July 29, 2019.

107. Merck Sharp \& Dohme Corp. Recombivax [package insert]. U.S. Food and Drug Administration website. www.fda.gov/media/74274/download. Accessed July 29, 2019.

108. Merck and Co. Gardasil [package insert]. U.S. Food and Drug Administration website. www.fda.gov/media/74350/download. Accessed July 29, 2019.

109. GlaxoSmithKline Biologicals. Bexsero [package insert]. U.S. Food and Drug Administration website. www.fda.gov/media/90996/download. Accessed July 29, 2019.

110. Pfizer. Prevnar 13 [package insert]. U.S. Food and Drug Administration website. www.fda.gov/media/107657/download. Accessed July 29, 2019. 